DISCUSIONES

\title{
CLARIFYING SINGER'S GOLDEN RULE
}

JAMES A. GOULD

University of South Florida

Tampa, Florida

For the first time in a number of years a philosophical journal has an article on the Golden Rule ${ }^{1}$ with the publication, "The Golden Rule," by Marcus Singer. ${ }^{2}$ He notes that there has been remarkably little philosophical discussion of it. This is true. Intuitionists (such as Ross), naturalists (such as Rice), and emotivists (such as Stevenson) never mention it. Surprisingly neither do the writers in religious ethics. Well-known religious ethicists, such as Ramsey ${ }^{3}$ and Niebuhr ${ }^{4}$ never mention it, let alone consider it to be a standard of at least some value.

Singer's conclusion is that "the Golden Rule has to be understood as a moral principle, and not as a moral rule. That is to say, it does not, as does o moral rule, state of some specifically determined kind of action that it is right or wrong, or that it ought or ought not to be done. It rather sets forth, or has to be understood as setting forth, in abstract fashion, a method or procedure for determining the morality of a line of action, and thus is intended to provide a principle from which, or in accordance with which, if it is valid, more specific or concrete moral rules can be derived." (294-95) "What the Golden Rule requires is that everyone ought to act in his relations with others on the same standards... that he would have them apply in their

1 Also see my "The Not-So-Golden Rule", Southern Journal of Philosophy, Fall 1963, pp. 10-14.

2 Philosophy, October 1963, pp. 293-314.

s Ramsey, Basic Cristian Ethics, New York, 1954.

- Niebuhr, R., An Interpretation of Cristian Ethics, New York, 1934. 
treatment of him, taking account of and respecting, but not necessarily acceding to, their wishes and desires." (313)

Thus Singer says that the Golden Rule is "not a substitute for a moral theory," but a "method .. . for determining a line of action." The point I wish to make is that the Golden Rule is not so much a method as it is an attitude with which to approach problems. Or what can be said is that what Singer means by method in this case is attitude. The Gol. den Rule provides us with the attitude or spirit with which to approach problems rather than any cognitive criteria. Or one can say it as follows: the Golden Rule tells us to do right and/or be good, but it does not tell us what the right and good are. To say, as Singer does, that it does not provide a moral theory means that it does not define the basic ethical terms; the Golden Rule asks (in Singer's terminology) that the same standard be applied, but it doesn't define the standard.

The Rule states: "Do unto others as you would have them do unto you." The meaning of this rule is: "Do unto others what you think it right for them to do unto you." The basic ethic term "right" is here undefined. As it is undefined each person seeks or borrows a definition for the term. For example, in his recent book, Ethics, C. Baylis says, "How can we restate it in an acceptable form?" One sug. gestion is ..., "act toward others in a way that will result in the greatest possible good for all concerned ..." 5 Right is defined in terms of good. Many other examples of defining the Golden Rule can be found in the history of Western philosophical thought. Heackel defined right in terms of evolutionary survival morality. In the early eighteenth century Samuel Clarke redefined the Rule: "Whatever I rightly judge reasonable or unreasonable for another to do for me; that, by the same judgment, I declare reasonable or unreasonable, that $I$ in the like case should do for him." ${ }^{~} \mathrm{He}$

5 Baylis, Ethics, New York: Holt, 1958, p. 99.

6 Samuel Clarke, Works, ed. B. Hoady, 1738, Vol. II, p. 619. 
interprets "rightly" to mean "with sound reason and for the public good." Thus Clarke as well as Baylis suggests or defines the Golden Rule in terms of good. This latter basic ethical term would then still have to be defined. Because the Golden Rule leaves these basic ethical terms undefined, an adherent to this doctrine must supply definitions.

The fact that the Golden Rule leaves the basic ethical terms undefined further explains an analysis of Weiss on this. He speaks of the Golden Rule as "a structure which has different import in each case," and again as "having different applications and meanings in different contexts." The reason why different imports or different meanings are possible is, in the main, due to the fact that "good" and "right" are undefined, and as different people define them differently at the same and different times, these different meanings and imports arise. This reasoning shows why, in spite of the fact that nearly every major religion expresses some form of the Golden Rule as a central doctrine, there exist such wide differences in ethical beliefs among these religions. How do these differences arise? This question is to ask, "Why do different cultures define "good" and "right" differently?" And the answer to this question is, of course, very complex. It is the product of the geographic, economic, climatic, and other factors which bring about cultural ethics.

The role of the culture as the provider of the definition of these undefined terms is very important. Few members of a social group are as sophisticated and creative as the philosophers Baylis, Clarke, and Haeckel. Consequently most members of a social group must turn to a definition already provided for them. Thus the society in which such an individual lives provides his definition of "right" and "good." That society, i.e., the customary ethical codes, should provide the meaning of "right" and "good" for the great majority of the people in it is a tautology. For what does "custo-

7 Weiss, P., Man's Freedom, New Haven, 1950, pp. 153-54. 
mary ethical code" mean except "what the majority of people accept?" The often unrecognized feature is that the follower of a Golden Rule ethic believes that this ethical rule provides the meaning of "good" and "right," while in truth these terms are left undefined by the Golden Rule, and it is his society which supplies the definition.

That the Golden Rule qua rule leaves these terms undefined may be more clearly grasped through examples. Consider the ethical problem of segregation. What ethical decision follows from the Golden Rule? Recently in a southern city the three possible positions regarding segregation were taken by three different Christian Churches: segregation is ethical, unethical, and neither ethical nor unethical. Each of these religious groups defined the basic ethical terms with reference to its own social custom ethic. That these terms are undefined in the Rule can be further realized when more problems in the area of justice are considered. What follows from the Rule in the case of the Fifth Amend. ment, Taft-Hartley, or socialized medicine? Concerning these problems one can find all positions, but the usual answer from members of a Golden Rule ethic is that ethics doesn't have anything to do with these problems, which is the customary attitude of United States society, viz., that these issues are not ethical ones. That reason is in part that these are considered customarily to be non-ethical issues in that most people in society are limited in their thoughts and actions to the consideration of their own well-being and to their relations with those people whom they encounter. This means that most problems of justice, etc., will not fall under customary consideration. Another fact emphasizing this point is that the major part of society does not consider the acts of great men (Ghandi, Darrow, Mill, etc.) either as "right" or as "being conducive to happiness."

Let me further establish my points with quotations from Kant and Mill. Kant protested against the Golden Rule. Note the following statement by this greatest of German philosophers: 
Let it not be thought that the common: quod tibi non vis fieri, etc. could serve here as the rule or principle... it cannot be a universal law, for it does not contain the principle of duties to oneself, nor of the duties of benevolence to others (for many a one would gladly consent that others should not benefit him, provided only that they might be excused from showing benevolence to them), nor finally that of duties of strict obligation to one another, for on this principle the criminal might argue against the judge who punishes him, etc. ${ }^{8}$

Thus Kant strongly reacts against the identification of the Categorical Imperative and the Golden Rule. This point was emphasized in conversations with this writer by the Kantian scholar, Julius Ebbinghaus. In the above quotation Kant recognize two negative aspects of the Golden Rule: first, that it contains nothing about duties to oneself. This last point would have significant consequences for any social group which adhered to the Golden Rule ethic. If there were no customary duties to develop one's own intellectual capacity, then such a society would place a low value on the intellect. In such cases economic success could well become the central value.

In the case of Mill a final and importante point is to be noted. Consider the following statement by Mill:

But others besides utilitarians have been of opinion that the Christian revelation was intended, and is fitted, to inform the hearts and minds of mankind with a spirit which should enable them to find for themselves what is right, and incline them to do it when found, rather than to tell them, except in a very general way, what it is; and that we need a doctrine of ethics, carefully followed out, to interpret to us the will of God. ${ }^{9}$

The important word here is spirit. The spirit that one

8 Kant, Foundations of the Metaphisics of Morals, tr. L. W. Beck (Univ. of Chicago Press, 1950), p. 88.

9 Mill, Utilitarianism (New York, 1948), Liberal Arts Press, p. 220. 
has towards something reflects his attitude or intent. The Golden Rule encourages us to be good. This is important in life, i.e., to be encouraged to be good. But the Golden Rule does not tell us what the good is. This latter statement is a main point of this paper. Thus although the Golden Rule does not tell us what the good is, it does encourage us to be good. It motivates us to be good:

The golden rule does not solve for us our ethical problems but offers only a way of approach. It does does not prescribe our treatment of others, but only the spirit in which we should treat them. ${ }^{10}$

This is its main - the important-value for society.

One can still adhere to the Golden Rule as a partial ethic. It must be realized, however, that the definition of the basic ethical terms, "good" and "right" (which is the main task of an ethic), must come from some other source than the Golden Rule. The schools of philosophical ethics-naturalism, intuitionalism, etc. - have attempted to provide the adequate definitions of right and good. Many contemporary writers in religious ethics realize the need to complete their theories with definite philosophical positions:

The fact is that Christianity as a whole always had to borrow from some scheme of rationalism to complete its ethical structure. The early church borrowed from Stoicism and Thomistic Catholicism, appropriated Aristote. lian doctrine to provide a foundation for its more distinc. tively Christian superstructure. ${ }^{11}$

Thus the general principles to which religious ethics must be related are ethical systems such as those developed by the great philosophers. The motivation provided by religious

10 McIver, "The Deep Beauty of the Golden Rule", Moral Principles of Action, (New York), 1952, p. 45.

11 Niebuhr, op. cit., p. 185. 
writings is not a necessary condition for an adequate philosophical ethic, but some philosophers do appeal to it.

In summation: I hope to have clarified Singer's article by showing: that the Golden Rule has left the basic ethical terms undefined; that it thus allows many interpretations reflecting the individual society's customs; and that nevertheless it may help motivate us to do good and avoid evil by providing the proper attitude. 